\title{
Sujeito, sociedade e tecnologia: a discur- sividade da rede (de sentidos)
}

\author{
Maristela Cury Sarian ${ }^{1}$
}

Cristiane Dias nos apresenta, nesta obra - parte da coleção Significação e História, publicada pela editora Hucitec - suas compreensões a respeito dos processos de subjetivação na chamada Sociedade da Informação. Mais especificamente, a autora analisa a maneira pela qual se estabelecem os laços sociais na discursividade eletrônica das salas de bate-papo HIV, dando visibilidade ao modo de produção material da vida que emerge na virtualidade do ciberespaço.

Inscrito na perspectiva da Análise de Discurso construída por Michel Pêcheux e Eni Orlandi, o trabalho traz contribuições importantes aos estudos não apenas da Linguística e da Língua Portuguesa, mas também às pesquisas empreendidas no âmbito da Comunicação e Informação, como Jornalismo, Publicidade, Ciências da Informação e da Documentação.

Neste livro, estruturado em três grandes partes, a autora nos convida a refletir, na primeira parte, sobre a constituição e o funcionamento do ciberespaço, em que as noções de tempo e espaço, ressignificadas pela internet, ganham relevo. Comparecem, nesse ponto do trabalho, as contribuições de autores como Wertheim (2001), a partir de quem Dias colhe exemplos da pintura, da literatura, da escrita, da arqueologia e das grandes navegações para mostrar como foi se construindo, na passagem da Idade Média para a Idade Moderna, uma nova concepção de espaço e de tempo, que marca, com o Renascimento, uma ruptura com o espaço aristotélico. Trajeto que possibilitou, no século XXI, que uma nova temporalidade fosse instalada, constituída pela existência virtual das coisas do mundo, efeito das novas condições materiais de produção.

A autora compreende o ciberespaço como um espaço discursivo, em sua forma material, como um espaço de significação, portanto, o que implica em considerá-lo como um espaço de linguagem, um espaço político-simbólico de construção de sentido, marcado por uma temporalidade organizada a partir do acontecimento instaurado pela internet. Esse espaço ciber, virtual, não localizável como um território do mundo físico, instituído pela tecnologia digital, possibilita, ao sujeito da contemporaneidade, novos rituais de circulação, novos costumes, novas maneiras de relação e de sociabilidade, novos modos de exercício de poder, novas ciências e formas de conhecimento, novas crenças possíveis: deslocamento, e não rompimento de sentidos.

Como efeito das mudanças de se habitar os lugares na organização do espaço, a autora destaca as novas maneiras de se construir conhecimento, permitidas pelos "artefatos de produção do conhecimento", como, por exemplo, acompanhar uma conferência e participar de eventos e debates pela internet. A velocidade com que as coisas-a-saber circulam nas instituições de saber, em outras redes institucionais, e não mais apenas em laboratórios, universida-

\footnotetext{
${ }^{1}$ Doutora em Linguística pela UNICAMP. Professora da Universidade do Estado de Mato Grosso (UNEMAT). E-mail: maristelasarian@gmail.com Endereço: Avenida: Tancredo Neves, nº1095, Cavalhada, CáceresMT. CEP: 78.200-000.
} 
des e escolas, produz o que a autora compreende como uma divisão do espaço institucional, em que convivem, no mesmo espaço, porém, não sem disputa, páginas de revistas especializadas e blogs de notícias, o que conduz a uma abertura às formas de saber e a uma mudança na relação do sujeito com a escrita, com a leitura, com a pesquisa: efeito de uma visão do mundo modificada, que afeta os sujeitos.

Nesse cenário, as salas de bate-papo são significadas como um espaço em que uma nova experimentação da vida se torna possível, nas quais se vê nascer um novo lugar de constituição desse sujeito. Um lugar em que se dá a ver o deslizamento de sentido de internet do técnico para o afeto: do acesso a dados informáticos à troca de informações entre investigadores do Departamento de Defesa norte-americano no início dos anos 1970, chega-se, no século XXI, às mensagens afetivas, que instituem a internet como um lugar do encontro.

É desse modo que a autora compreende a rede como um lugar de autoria, em que o sujeito projeta para si uma unidade imaginária nessa necessidade de se dizer, experimentar-se, legitimar-se, ser visível: falar de si é constitutivo não apenas das salas de bate-papo, mas também de ambientes como $b \log s$, redes sociais, páginas pessoais e as que se destinam a conhecer pessoas, fotoblogs e grupos de discussão.

Dias começa a nos apresentar, já nessa primeira parte do trabalho, o funcionamento desse espaço por meio da descrição da sala. Um ambiente que funciona na evidência do saber, o que demanda do sujeito o conhecimento técnico da rede, condição primeira para esse sujeito poder (se) dizer. Dá-se relevo à segmentação temática dos grupos, o que produz o efeito de seleção dos participantes desejados em cada sala. Entrar em uma determinada sala não é da ordem de uma escolha individual, consciente, pois efeito do processo de identificação dos sujeitos com os sentidos: o que se mostra na evidência de uma escolha é, antes, efeito do processo de interpelação ideológica. É por meio desse processo que o sujeito vai habitando o ciberespaço, nele circulando e nele criando seus laços de pertencimento.

Nesse gesto de descrição, comparece também a nomeação do participante, que se dá pela injunção ao nomear-se, pela criação de um nickname. Instala-se, assim, um processo fluido de identificação, por meio do qual se dá visibilidade à identidade virtual desse sujeito que se constitui no ciberespaço, ao mesmo tempo em que essa identidade estabelece uma relação com o mundo físico: marcas linguísticas recortadas do material vêm dizer da localidade, em formulações como "de onde tecla?", e da idade, como em "Chubby29SP", inscrita no nickname: cria-se, assim, o corpo textual.

Na segunda parte do livro, Dias mostra o caráter comunitário da sala, em que é possível teclar reservadamente ou com vários sujeitos ao mesmo tempo. Um teclar que, ao se valer de uma escrita particular, "invenção constitutiva do sujeito", vem dizer da manifestação do corpo físico na sala de bate-papo, um gesto compreendido como a inscrição do corpo na língua, efeito da relação desse sujeito com a escrita, o que a autora chama de corpografia: um corpo sem órgãos (DELEUZE, 2000); um corpo simbólico que se textualiza na imbricada relação grafia, afeto e tecnologia. Nesse processo de textualização do corpo, comparece uma escrita que deixa rastros, vestígios do sujeito nesse corpo-imagem, corpo-linguagem, corposujeito, corpo-grafia.

No caso específico da sala HIV, enquanto lugar de identificação do sujeito soropositivo, o corpo desse sujeito, significado pela doença, encontra, por meio da escrita construída no bate-papo, a possibilidade de produzir sentidos outros para esse corpo. O corpo é, portanto, lugar material no qual a significação acontece; é a partir dele que as relações no espaço virtual se reorganizam. 
A autora avança nas compreensões a respeito da inscrição do corpo nas salas de batepapo na terceira parte da obra, tomando a formulação "alg afim de tc?", a qual é vista como parte de um ritual instalado no jogo, no acontecimento da sedução; palavras que se repetem por meio do teclar, e não do olhar: uma regularidade que atualiza uma memória que se desloca nesse gesto de dizer. É por meio dessa pergunta, a qual não necessita de resposta para que se inicie a troca de mensagens, que o sujeito se torna visível e se inscreve no funcionamento discursivo desse ambiente.

As salas de bate-papo são, portanto, locais de significação de si e do outro; espaços de afetividade que impulsionam emoções, sentimentos, militância, encontros, desencontros, amorosos ou não - a formulação da pergunta "o q rola nessa sala" dá vazão a sentidos para além do ritual amoroso. As salas, antes, são espaço de resistência para a subjetividade dominante, à medida que o sujeito é posto em confronto com sua própria constituição material, na história. É desse modo que a autora compreende que, nessas salas, se instaura o processo de interpelação do sujeito-da-tecnologia, esse sujeito evanescente, marcado pela multiplicidade, no qual a técnica interpela o indivíduo em sujeito na relação ciberespacial.

Ao longo do livro, Dias chama atenção para os efeitos que essa nova reorganização do espaço, que desloca sentidos do mundo físico para o mundo virtual, produz no que tange aos dispositivos de poder e suas formas de controle do sujeito. Esse sujeito subjetivado no ciberespaço, que tem um modo de ser sujeito possibilitado pela sala de bate-papo, é regido, na sociedade de controle como a nossa, pelos mecanismos ora mais, ora ou menos coercitivos, provenientes da própria tecnologia digital. A autora cita como exemplo o caso de crimes virtuais, nos quais as investigações se voltam para o rastreamento do computador, visando à identificação do IP, que representa, aos olhos do Estado, uma identidade fixa e identificável: o ponto de ancoragem é o numérico, é a senha.

No que diz respeito à produção de sentido para o corpo soropositivo brasileiro na rede, a memória discursiva em funcionamento em nossa sociedade é aquela do corpo projetado pela mídia de massa, considerada como uma instância de poder. A autora recupera a imagem do cantor Cazuza, divulgada na televisão brasileira, a qual colocava em evidência o corpo marcado pelo estigma da doença, para mostrar que o sentido de corpo real produz efeitos no modo de constituição desse sujeito nas salas de bate-papo. Dias analisa mensagens nas quais se projeta um imaginário de corpo não saudável, colocando em relação sequências discursivas nas quais comparecem, por um lado, a descrição fisiológica desse corpo, inscrita na discursividade da medicalização, e, por outro lado, se dá relevo ao corpo inscrito na lógica do seja saudável: efeito dos modos de individuação do sujeito no ciberespaço. É, portanto, no batimento entre o uno e o múltiplo, entre unidade e dispersão, na dobra do real que se dá corpo ao sentido e sentido ao corpo a um sujeito materialmente significado, individuado, subjetivado no espaço-tempo virtual: efeito do real da história na relação com o real da língua.

Para finalizar, trago um recorte com o qual a autora produz o efeito de fecho de sua pesquisa:

(00:29:24) LINCK: Bom, bom papo para os que ficam... boa noite...

(22:22:49) Fernando® ama Juß.: Bem, espero q todos tenham uma boa noite e uma linda semana!!!!!!!!

(22:23:06) Fernando® ama Ju®.: Fiquem com Deus ! Até !

(01:47:20) PINTORS reservadamente fala para TODOS: MEUS AMADOS AMIGOS, QUE TIVE O PRAZER DE TC HOJE, QUERO DESEJAR UMA BOA NOITE VOU NANAR

Boa leitura! 


\section{Referência:}

DIAS, Cristiane. 2012. Sujeito, sociedade e tecnologia: a discursividade da rede (de sentidos). São Paulo: Hucitec. 